\title{
ESTIMATIVA DA DEMANDA HÍDRICA DA CULTURA DO GIRASSOL NO MUNICÍPIO IPAMERI-GO
}

\section{ESTIMATION OF THE WATER DEMAND OF THE SUNFLOWER CULTURE IN THE IPAMERI-GO MUNICIPALITY}

\author{
Rafael Guimarães Silva Moraes ${ }^{1}$; Elton Ferreira Lima²; Jossimara Ferreira Damascena ${ }^{3}$; \\ Rakel Ferreira Alves ${ }^{4}$; Wilson Araújo da Silva ${ }^{5}$
}

DOI: https://doi.org/10.31692/978-65-991061-7-0.351-356

\section{INTRODUÇÃ̃O}

No momento de implantar determinada cultura, o produtor deve compreender a necessidade hídrica, para quantificar o volume de água necessário durante o seu ciclo de desenvolvimento. Para tal, determinar os períodos em que a cultura se encontra susceptível a falta de água é em última análise de fundamental importância para reduzir perdas de rendimento (CARVALHO et al., 2013).

A demanda hídrica de uma determinada cultura pode ser entendida como sua procura evapotranspirativa em um determinado ambiente quando submetida a determinados tratos culturais (PEREIRA, 2007).

A FAO (Organização das Nações Unidas para Agricultura e Alimentação) sugere estimar a demanda hídrica das culturas de interesse econômico através do método do coeficiente de cultivo único $(\mathrm{ETc}=\mathrm{Kc}$.ETo), em que, ETo é a evapotranspiração de referência e Kc é o coeficiente de cultivo empírico da cultura (LYRA et al. 2012). Assim, a necessidade hídrica pode ser obtida, de forma bastante simplificada, através do valor da evapotranspiração de uma cultura de referência (ETo) corrigida pelo coeficiente da cultura (Kc), que dependente do tipo de cultura e de seu estágio de desenvolvimento (SILVA et al. 2015).

O girassol está entre as principais espécies cultivadas no município Ipameri-GO. Segundo o IBGE (2017) a área plantada com a cultura é de 1607 hectares, colhendo anualmente cerca de 3157,2 toneladas da semente.

Diante disso, o presente estudo foi desenvolvido com o objetivo de estimar a demanda de hídrica para a cultura do girassol, no município de Ipameri, Estado de Goiás, fornecendo dados de fundamental importância para auxiliar técnicos e produtores rurais na definição de

\footnotetext{
1 Graduação em engenharia agronômica, Universidade Estadual da Região Tocantina do Maranhão, r.f_guimaraes@hotmail.com

${ }^{2}$ Graduação em engenharia agronômica, Universidade Estadual da Região Tocantina do Maranhão, elton110@ @otmail.com

${ }^{3}$ Graduação em engenharia agronômica, Universidade Estadual da Região Tocantina do Maranhão, jossi_agro@hotmail.com

${ }^{4}$ Graduação em engenharia agronômica, Universidade Estadual da Região Tocantina do Maranhão, rakelbt10@ gmail.com

${ }^{5}$ Professor Dr, Universidade Estadual da Região Tocantina do Maranhão, wilsonufrrj@yahoo.com.br
} 
um período de semeadura favorável para a cultura da melancia com o objetivo de evitar a redução da produtividade em decorrência do estresse hídrico, por falta de água.

\section{FUNDAMENTAÇÃO TEÓRICA}

O girassol (Helianthus annuus L.) foi introduzido no Brasil no final do século XIX pelos colonos europeus (Ribeiro, 2008) e se adapta a diferentes condições edafoclimáticas, podendo ser cultivado desde o Rio Grande do Sul até Roraima (LEITE et al., 2007). Essa cultura vem tornando-se expressiva no cenário nacional, devido à qualidade do óleo comestível extraída dos aquênios, ao aproveitamento dos subprodutos em rações para animais, ser alternativa econômica aos sistemas de cultivo (Backes et al., 2008; Porto et al., 2007) e, principalmente, à possibilidade da utilização do óleo na fabricação de biodiesel (YOKOMIZO, 2003).

O requerimento de água pelo girassol varia de 600 a $1.000 \mathrm{~mm}$ em seu ciclo vegetativo sob condições de primavera-verão em climas temperados. A evapotranspiração aumenta no período de florescimento, e pode atingir entre 12 e 15 mm.dia ${ }^{-1}$ (GOMES, 2005).

O estresse por deficiência hídrica é o principal determinante do rendimento do girassol, muito em parte ao seu efeito sobre a área foliar. A falta de água nos tecidos desfavorece a expansão foliar e leva a uma menor área foliar. Esse é o principal mecanismo de defesa das plantas contra a falta d'água, já que com menor área foliar haverá menores perdas por evapotranspiração. Na cultura do girassol, quando o estresse hídrico ocorre precocemente há um desenvolvimento foliar apenas moderado, com redução do vigor da planta e do número de folhas (GAZZOLA et al., 2012).

Portanto, a insuficiente disponibilidade de água para a planta de girassol pode afetar de forma diferenciada e variável os parâmetros de rendimento da cultura, principalmente o número de aquênios e o tamanho do capítulo, ambos com boa correlação com a produtividade (GAZZOLA et al., 2012).

\section{METODOLOGIA}

O presente estudo foi realizado na região Oeste do estado de Goiás, mais precisamente no município de Ipameri, localizado entre as coordenadas geográficas $17^{\circ} 43^{\prime} 19^{\prime}$, de latitude $\mathrm{S}$ e $48^{\circ} 09^{\prime} 35^{\prime}$ " de longitude $\mathrm{W}$, com altitude média de 764 metros acima do nível do mar. $\mathrm{O}$ clima da região segundo a classificação de Köppen é do tipo Aw, tropical quente e úmido, com precipitações mal distribuídas, e duas estações: a da chuva, que vai de outubro a abril, e a da seca, que vai de maio a setembro. 
Segundo o Instituto Nacional de Meteorologia (INMET), a média pluviométrica anual é de $1437 \mathrm{~mm}$, a do mês mais chuvoso (dezembro) é de $300 \mathrm{~mm}$ e do mês mais seco (junho) de $9 \mathrm{~mm}$. A temperatura média anual é de aproximadamente $23,9{ }^{\circ} \mathrm{C}$ e a umidade relativa média do ar é de aproximadamente $66 \%$.

Os dados meteorológicos necessários para execução desse trabalho foram retirados do banco de dados do Instituto Nacional de Meteorologia (INMET), utilizando-se uma série histórica contínua de 18 anos (2000-2017) dos elementos climáticos que foram utilizados na equação de Penman-Monteith-FAO (EToPM) para estimativa da evapotranspiração de referência.

Por meio do software Microsoft Office Excel® (2013) foram calculadas as estimativas da evapotranspiração de referência pelo método de Penman-Monteith-FAO (EToPM) para esssa localidade (ALLEN et al., 1998), através da Equação 1, descrita abaixo.

$$
\mathrm{ETo}=\frac{\left[0,408 \cdot \Delta \cdot(\mathrm{Rn}-\mathrm{G})+\left(900 \cdot \mathrm{U}_{2} / \mathrm{T}+273\right) \cdot(\mathrm{es}-\mathrm{ea})\right]}{\Delta+\gamma \cdot(1+0,34 \cdot \mathrm{U} 2)}
$$

em que;

ETo $=$ evapotranspiração de referência, $\mathrm{mm} \mathrm{dia}^{-1} ; \Delta=$ declividade da curva de pressão, $\mathrm{kPa}^{\circ}{ }^{\circ} \mathrm{C}^{-1} ; \mathrm{Rn}=$ saldo de radiação, $\mathrm{MJ} \mathrm{m}^{-2} \mathrm{dia}^{-1} ; \mathrm{G}=$ fluxo de calor, $\mathrm{MJ} \mathrm{m}^{-2} \mathrm{dia}^{-1} ; \gamma=$ constante psicrométrica, $\mathrm{MJ} \mathrm{kg}^{-1} ; \mathrm{T}=$ temperatura média, $\left.{ }^{\circ} \mathrm{C}\right) ; \mathrm{U}_{2}=$ velocidade do vento, $\mathrm{m} \mathrm{s}^{-1}$; es = pressão de saturação de vapor, $\mathrm{kPa}$; ea = pressão de vapor, $\mathrm{kPa}$;

De posse dos valores da evapotranspiração de referência (ETo) foi realizada a estimativa da demanda hídrica da cultura do girassol para a região de estudo, através da Equação 2, recomendada por Bernardo et al. (2008) e descrita abaixo.

$\mathrm{ETc}=\mathrm{ETo} . \mathrm{Kc}$

em que;

ETc $=$ Demanda hídrica da cultura de interesse econômico $\left(\mathrm{mm} \cdot \mathrm{dia}^{-1}\right)$;

ETo $=$ Evapotranspiração da cultura de referência $\left(\mathrm{mm} \cdot \mathrm{dia}^{-1}\right)$;

$\mathrm{K}_{\mathrm{C}}=$ Coeficiente de Cultivo (adimensional), tabelado.

A Tabela 1 descreve os valores de Kc (Coeficiente de cultivo) inicial, médio e final da cultura do girassol, estes valores (tabelados) estão disponíveis no boletim FAO-56.

Tabela 1: Kc inicial, médio e final da cultura do girassol. Fonte: Boletim 56-FAO.

\begin{tabular}{cccc}
\hline Cultura & Kc_inicial & Kc_Médio & Kc_Final \\
\hline Girassol & 0,35 & 1,15 & 0,35 \\
\hline
\end{tabular}

Nota-se que o valor do coeficiente de cultivo está diretamente relacionado com a fase de desenvolvimento da cultura, sendo pequeno no início (Kc inicial), e cresce chegando ao ponto máximo no pleno desenvolvimento da cultura (Kc médio) e depois decresce, no estádio final do ciclo (Kc final). 


\section{RESULTADOS E DISCUSSÕES}

A Tabela 2 apresenta a demanda hídrica total estimada para a cultura do girassol no município de Ipameri-GO, que foi de 221,62 mm. Observa-se nesta tabela que o período de maior demanda hídrica compreende a fase de desenvolvimento vegetativo com 53,82 $\mathrm{mm}$ e a fase de floração com 109,61 mm. Esses resultados corroboram com os encontrados por Acosta (2009) que em seu trabalho de estimativa do consumo hídrico da cultura do girassol no município de Chapada do Apodi - RN, também observaram que o período de maior demanda hídrica é na fase do desenvolvimento vegetativo e floração.

Outro resultado semelhante foi encontrado por Carvalho et al., (2012) que ao estimar a demanda hídrica da cultura do girassol no munípio de São Cristóvão-SE, verificou-se que a evapotranspiração da cultura foi de $219,30 \mathrm{~mm}$.

Tabela 2: Coeficientes de cultura (Kc) e estimativa da demanda hídrica por fase fenológica, para a cultura do

\begin{tabular}{|c|c|c|c|c|c|c|}
\hline Fase Fenológica & $\begin{array}{l}\text { Início da } \\
\text { fase }\end{array}$ & $\begin{array}{c}\text { Duração } \\
\text { (dias) }\end{array}$ & $\begin{array}{c}\text { ETo } \\
\left(\text { mm.dia }^{-1}\right)\end{array}$ & Kc & $\begin{array}{c}\text { ETc } \\
\left(\text { mm.dia }^{-1}\right)\end{array}$ & $\begin{array}{c}\text { ETc-Fase } \\
\left(\mathrm{mm}^{-d i a}{ }^{-1}\right)\end{array}$ \\
\hline Fase Inicial & 01/jun & 28 & 3,01 & 0,35 & 1,05 & 29,50 \\
\hline D. Vegetativo & 29/jun & 15 & 3,12 & 1,15 & 3,59 & 53,82 \\
\hline Floração & 14/jul & 27 & 3,53 & 1,15 & 4,06 & 109,61 \\
\hline M. Fisiológica & 10/ago & 20 & 4,10 & 0,35 & 1,44 & 28,70 \\
\hline \multicolumn{6}{|c|}{ Demanda Hídrica Total da Cultura do Girassol (mm) } & 221,62 \\
\hline
\end{tabular}

A Figura 1 apresenta o gráfico comparativo entre a demanda hídrica acumulada, correspondente as fases fenológicas da cultura do girassol e a precipitação acumulada ocorrida nas respectivas fases no município de Ipameri-GO. Essa informação é de extrema importância para verificar a possível ocorrência de deficit hídrico em fases específicas do desenvolvimento do girassol e buscar alternativas para minimizar seus impactos negativos na produção. A análise da Figura 1 permite compreender a viabilidade da adoção da agricultura de sequeiro para a cultura do girassol no município de Ipameri-GO.

Figura 1. Demanda hídrica acumulada estimada para as fases e precipitação acumulada ocorrida nas respectivas fases. Fonte: Própria

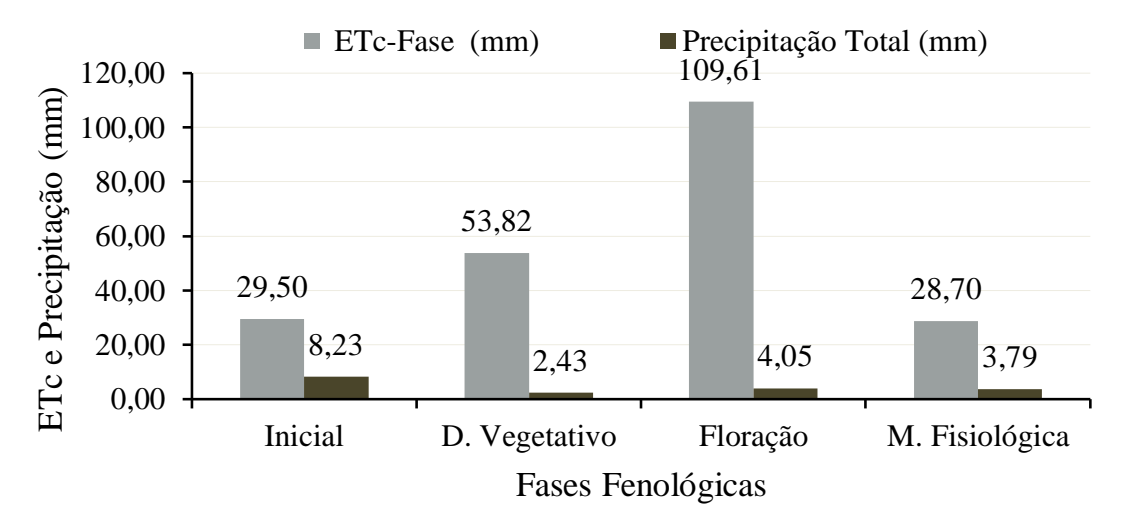


Nota-se que para o período considerado (01/junho à 29/agosto) há limitação hídrica para o cultivo de sequeiro da cultura do girassol na região de Ipameri-GO, pois não há suprimento hídrico necessário para o adequado desenvolvimento da cultura em nenhuma de suas fases, sendo desta forma, necessário a utilização de sistemas de irrigação.

\section{CONCLUSÕES}

A necessidade hídrica estimada para a cultura do girassol, da fase inicial até a maturação fisiológica, no município de Ipameri-GO, foi de 221,62 mm.

No município de Ipameri-GO, não tem como produzir girassol no período analisado, visto que há limitação hídrica para o cultivo de sequeiro da cultura em todas as fases do desenvolvimento fenológico.

\section{REFERÊNCIAS}

ACOSTA, J. F.; Consumo hídrico da cultura do girassol irrigada na região da chapada do apodi - RN. Dissertação de mestrado. Campina Grande-PB, 2009

ALLEN, R. G.; Pereira, L. S.; RAES, D.; SMUTH, M. Crop Evapotranpiration: Guidelines for computing crop water requirements, Rome: FAO, 1998, 301p

BACKES, R. L. et al. Desempenho de cultivares de girassol em duas épocas de plantio de safrinha no planalto norte Catarinense. Scientia Agraria, v. 9, n. 1, p. 41-48, 2008

BERNARDO, S.; SOARES, A.A.; MANTOVANI, E.C. Manual de irrigação. 8. ed. Viçosa, MG: UFV, 2008. 625p.

CARVALHO, R. S.; FILHO, J. S. S.; MENEZES, F. S.; DAMASIO, A. O. C.; SANTANA, L. O. G.; FACCIOLI, G. G.; Determinação da demanda hídrica da cultura do girassol irrigada com água residuária em condições de casa de vegetação em são Cristóvão-SE. XXV CONIRD - Congresso Nacional de Irrigação e Drenagem, São cristóvão-SE, 2012

CARVALHO, R.I.; KORCELSKI, C.; PELISSARI, G.; HANUS, A.D.; ROSA, G.M. Demanda hídrica das culturas de interesse agronômico. Enciclopédia biosfera, Centro Científico Conhecer - Goiânia, v.9, n.17; p. 2013.

GAZZOLA, A.; FERREIRA, C. T. G.; CUNHA, D. A.; BORTOLINI, E.; A cultura do girassol. Universidade de São Paulo Escola Superior de Agricultura. Departamento de Produção Vegetal. Piracicaba,SP, 2012.

GOMES, E.M. Parâmetros básicos para a irrigação sistemática do girassol (Helianthus annuus L.). 2005. 117f. Tese (Doutorado) - Universidade Estadual de Campinas, Campinas, SP.

INSTITUTO BRASILEIRO DE GEOGRAFIA E ESTATÍSTICA (IBGE), Censo Agropecuário, 2017. Disponível em < https://cidades.ibge.gov.br>Acesso em 12 set 2018 
LEITE, R. M. V. B. de C. et al. Indicações para o cultivo de girassol nos Estados do Rio Grande do Sul, Paraná, MatoGrosso do Sul, Mato Grosso, Goiás e Roraima. EmbrapaCNPSo, Londrina, 2007. 4 p. (Comunicado Técnico, 78).

LYRA, G.B.; SILVEIRA E.L.; LYRA G.B.; PEREIRA, C.R.; SILVA; L.D.B.; SILVA G.M.; Coeficiente da cultura da cana-de-açúcar no estádio inicial de desenvolvimento em campos dos Goytacazes, RJ. Revista Irriga, v. 17, n. 1, p. 102-113, jan/mar. 2012.

PEREIRA, L. S. Necessidades de água em regadio. CYTED y Universidad de Cuenca. Cuenca/Ecuador. Julho de 2007.

PORTO, W. S.; CARVALHO, C. G. P.; PINTO, R. J. B. Adaptabilidade e estabilidade como critérios para seleção de genótipos de girassol. Pesquisa Agropecuária Brasileira, v. 42, p. 491- 499. 2007.

RIBEIRO, J. L. Manejo da cultura do girassol no MeioNorte do Brasil. Embrapa MeioNorte, Teresina, 2008. 9 p. (Circular Técnica, 48).

SILVA, V. P. R.; GARCÊZ, S. L. A.; SILVA, B. B.; ALBUQUERQUE, M. F.; ALMEIDA, R. S. R. Métodos de estimativa da evapotranspiração da cultura da cana-de-açúcar em condições de sequeiro. Revista Brasileira de Engenharia Agrícola e Ambiental, v.19(5): 411-417, 2015.

YOKOMIZO, E. O combustível do girassol. CREA, Curitiba, n. 21, p. 18-23, 2003. 